\title{
A Regional Analysis of $\alpha$-Spectrin in the Isolated Mauthner Neuron and in Isolated Axons of the Goldfish and Rabbit ${ }^{1}$
}

\author{
EDWARD KOENIG ${ }^{2}$ AND ELIZABETH REPASKY*
}

State University of New York, Department of Physiology, Division of Neurobiology, Buffalo, New York 14214 and *Department of Molecular Immunology, Roswell Park Memorial Institute, Buffalo, New York 14263

\begin{abstract}
Isolated dendrites, somata, and desheathed axons of the goldfish Mauthner neuron (M-cell), in addition to other isolated myelin sheath-free axons of the goldfish spinal cord and of rabbit lumbar ventral roots, were shown by immunochemical and immunofluorescence techniques to contain $\alpha$ spectrin (fodrin). $\alpha$-Spectrin appeared to be organized as a randomly distributed reticular network, localized to the surface of isolated neuronal cellular structures. In addition, $\alpha$ spectrin was also distributed nonrandomly at specialized cellular sites. These sites included synaptic junctions and morphologically differentiated nodes of Ranvier (i.e., rabbit axons, but not goldfish axons). At the latter sites, it is possible to demonstrate that $\alpha$-spectrin is co-localized with Factin, as indicated by a striking correspondence of fluorescent images due to double labeling, using the indirect immunofluorescence technique with $\alpha$-spectrin antiserum, and direct binding of F-actin by rhodamine-conjugated palloidin. However, the spectrin-actin network at synaptic junctions appears to be distributed over the entire area of junctional contact and is not just restricted to postsynaptic densities. The possibility of a duality of roles of spectrin in membranerelated motile and anchorage functions is discussed.
\end{abstract}

Spectrin is a high molecular weight heterodimer originally identified as a membrane-associated protein in erythrocyte ghosts (Marchesi and Steers, 1968; Clarke, 1971; Fairbanks et al., 1971). Later, it was shown that spectrin was an F-actin-binding protein and that short, oligomeric actin segments, cross-linked by spectrin, probably formed a two-dimensional cytoskeletal framework underlying the erythrocyte membrane (Hainfeld and Steck, 1977; Brenner and Korn, 1979,1980 ). Largely because there was an apparent lack of immunological labeling of other cell types by antisera to mammalian erythrocyte spectrin (Painter et al., 1975; Hiller and Weber, 1977), a decade passed after its initial discovery before it became evident that spectrin-like proteins were, indeed, widely distributed among many nonerythroid cells, including cells of the nervous system (Goodman et al., 1981; Bennett et al., 1982b; Burridge et al., 1982; Glenny et al., 1982a, b; Palfrey et al., 1982; Repasky et al., 1982).

Received May 25, 1984; Revised August 6, 1984;

Accepted August 10, 1984.

\footnotetext{
${ }^{1}$ We thank Ms. Terry Crumb for her technical assistance, Mrs. Jean Seiler for typing, and Mrs. Julie Lakatos for photography. In addition, we thank Drs. Donald Faber and Maicolm Wood for the benefit of their discussion. This research was supported by Grant BNS $81-17219$ from the National Science Foundation.

${ }^{2}$ To whom correspondence should be addressed.
}

In brain tissue, however, spectrin-like protein was described and isolated as a result of independent lines of investigation. In one case, an analogous protein was first noted as a high molecular weight doublet undergoing axoplasmic transport (Lorenz and Willard, 1978) and, when later isolated and characterized, it was called fodrin (Levine and Willard, 1981). In the second case, an investigation of calmodulin-binding activity in brain also led to the isolation of the homologous protein, named calspectin (Kakiuchi et al., 1982). Current evidence indicates that fodrin (calspectin) is related to erythrocyte spectrin in structure, in cellular localization and, in F-actin-and calmodulin-binding properties, as well as in immunological crossreactivity. This has been used as a compelling argument for the view that spectrin-like polypeptides constitute a family of proteins with similar functions, a circumstance analogous to that of myosin, and that, therefore, spectrin should be retained as a generic name. Differences, nonetheless, between erythrocyte and brain spectrins have been reported, most notable of which are differences in the subunit composition and degree of structural homology (Bennett et al., 1982a, b; Burridge et al., 1982; Glenny et al., 1982a, b).

In this paper, we utilize the isolated Mauthner neuron of the goldfish and selected desheathed axons isolated from the goldfish brainstem and spinal cord and from lumbar ventral roots of the rabbit to examine the regional content and localization of a polypeptide that cross-reacts with chicken erythrocyte $\alpha$-spectrin antiserum. The Mauthner neuron, which is electrophysiologically and morphologically identifiable, is among the largest of vertebrate neurons, and its size lends itself to microanalytical and cytochemical studies of its cellular subdivisions. We confirm that a cytoskeletal network containing $\alpha$-spectrin is distributed throughout the soma, dendrites, and axon of the Mauthner neuron. In general, the network is distributed randomly and localized near the surface; however, the spectrin network is also distributed in a nonrandom manner at synapses and nodes of Ranvier. In addition, we demonstrate by indirect means that $\alpha$-spectrin is co-localized with F-actin at specialized cellular sites.

\section{Materials and Methods}

$\alpha$-Spectrin antiserum. Details regarding the preparation and characterization of $\alpha$-spectrin antiserum have been described previously (Repasky et al., 1982). Briefly, a chicken erythrocyte cytoskeletal residue was solubilized after cell lysis and fractionated by two-dimentional polyacrylamide gel electrophoresis. The $\alpha$-spectrin was cut out of the gel, emulsified in Freund's complete adjuvant, and used to immunize a rabbit. Immunoradiography and immunofluorescence indicated cross-reactivity of the antiserum with tissues of the CNS and PNS of the mouse and chicken, in addition to other nonerythroid tissues (Repasky et al., 1982).

Isolation of microscopic cellular samples. Experiments reported here were conducted exclusively on cellular material that was isolated by hand. The two Mauthner neurons (M-cells), consisting of the soma and the large lateral and ventral dendrites, were dissected from a goldfish brainstem tissue slice. The slice included the rostral half of the cerebellar crests; i.e., a segment extending from midway between the facial lobe and cerebellum to the caudal 
half of the cerebellar peduncles. The Mauthner cell axon (M-axon) was isolated by translating the axon out of its myelin sheath from a spinal cordbrainstem segment of variable length (e.g., 1 to $3 \mathrm{~cm}$ ) with a pair of no. 5 microtweezers (Koenig, 1965, 1978). The same technique was used to isolate axons, free of myelin sheath, from goldfish brainstem-spinal cord segments and from rabbit lumbar ventral root segments $(0.5$ to $1 \mathrm{~cm})$. Cellular samples were isolated in one of the following zinc-containing solutions: (a) $5 \mathrm{~mm}$ zinc acetate, $135 \mathrm{M} \mathrm{NaCl}, 5 \mathrm{mM} \mathrm{KCl}, 1.9 \mathrm{~mm} \mathrm{MgCl}, 20 \mathrm{~mm}$ HEPES ( $\mathrm{pH} 7.3$ with Tris); or (b) $5 \mathrm{~mm}$ zinc acetate, $0.1 \mathrm{M}$ guanidine hydrochloride (Schwarz-Mann), and $0.1 \mathrm{M}$ taurine (Sigma) ( $\mathrm{pH} \mathrm{6.5).} \mathrm{As}$ previously noted (Koenig, 1978), zinc inhibits endogenous calcium-activated protease activity and stabilizes cytoskeletal structure. Solution a was generally used to isolate samples for immunocytochemical experiments because the cellular material is more compliant and sticks more readily to a glass surface, and solution b was generally used to isolate samples for microanalytical purposes because it facilitates isolation, particularly of long segments of axons.

Preparative procedure for sodium dodecyl sulfate microelectrophoresis. Isolated microscopic samples used for sodium dodecyl sulfate (SDS) microelectrophoresis were deposited onto the surface of a split no. 2 coverslip (1.1 $\times 4 \mathrm{~cm}$ ). M-cells were deposited with dendrites extended in a droplet of solution b, and excess fluid was removed. Axons in suspension were plucked out into air by their ends and were collected as a clump on the tip of a 50 $\mu \mathrm{m}$ nichrome wire. The axon clump was deposited onto a coverslip and wetted briefly with distilled water so that it would stick, after which the fluid was immediately removed and the clump was dried in air. The cellular material was extracted successively with $70 \%$ ethanol and chloroform:methanol $(2: 1, v / v)$ by immersion, and then dried. The coverslip was transferred to an oil chamber, where the microscopic samples were placed over a well filled with paraffin oil. All subsequent processing steps were carried out on the stage of a phase-contrast microscope with the aid of a micropipette or a microneedle attached to a deFonbrune micromanipulator Dendrites were severed from the $\mathrm{M}$-cell by judicious wetting of a narrow segment of the soma-dendrite transition zone with the solvating medium (see below), using the micropipette tip to form a cleavage channel through the cellular process (Fig. 1). Dendrites or somata were then wetted sufficiently to dislodge them in order to transfer them to separate locations for solubilization.

Microscopic samples were solubilized with $1 \%$ SDS, $0.05 \mathrm{M}$ Tris borate, 1 mM EDTA, and $0.02 \mathrm{M}$ dithiothreitol. Brief heating ( $2 \mathrm{~min}$ ) was used to facilitate solubilization of axon clumps. Aliquot volumes were taken up by micropipette and expelled into slits of a specialized gel microslab system $(22 \times 30 \times 0.3$ $\mathrm{mm}$ ) for SDS microelectrophoresis (E. Koenig, unpublished procedure; details will be described elsewhere). The microslab gels were composed of $0.25 \%$ agarose and $7 \%$ polyacrylamide; they were equilibrated and stored in 0.04 M Tris, $0.04 \mathrm{M}$ glycine, $0.2 \%$ SDS, $30 \%$ urea, and $10 \% \mathrm{~T}-10$ dextran (Pharmacia). In preparation for a run, a gel microslab was removed from the storage buffer, blotted on glassine powder paper (Lilly) until the surface buffer was removed, laid onto a no. 2 coverslip $(22 \times 30 \mathrm{~mm})$, and placed over the well of an oil chamber. Slits were formed in the gel with a microneedle to accommodate solubilized samples. The gel microslab was placed over an oil well of a specially designed chamber for microelectrophoresis. After microelectrophoresis the gel was fixed by immersion in 30\% ethanol.

Immunoradiography. Immunoradiography (Burridge, 1978) was performed as described by Granger and Lazarides (1980), except that the gels were washed for 1 day after removal of antiserum or radioiodinated protein A. After immunolabeling and reaction with ${ }^{125}$-protein A (New England Nuclear), the gels were stained with silver according to the method of Switzer et al. (1979) and dried to a glass slide. Dried gels were pressed against strips of Kodak X-Omat AR film and exposed with dessicant at room temperature.

Immunofluorescence. The preparative procedure was as follows. M-cells and axons were deposited fully extended on a coverslip $(22 \times 22 \mathrm{~mm})$ surface in solution a (Fig. 2). The samples were fixed for $5 \mathrm{~min}$ by immersion in $1.8 \%$ formaldehyde, $5 \mathrm{~mm}$ zinc acetate, and $0.1 \mathrm{M}$ sodium cacodylate $(\mathrm{pH}$ $7.8)$ and washed twice in TM buffer $(10 \mathrm{~mm}$ Tris- $\mathrm{HCl}, 130 \mathrm{~mm} \mathrm{NaCl}, 5 \mathrm{~mm}$ $\mathrm{KCl}, 5 \mathrm{mM} \mathrm{NaN}_{3}, 5 \mathrm{mM} \mathrm{MgCl}$, pH 7.5). One part primary antiserum (1:10)
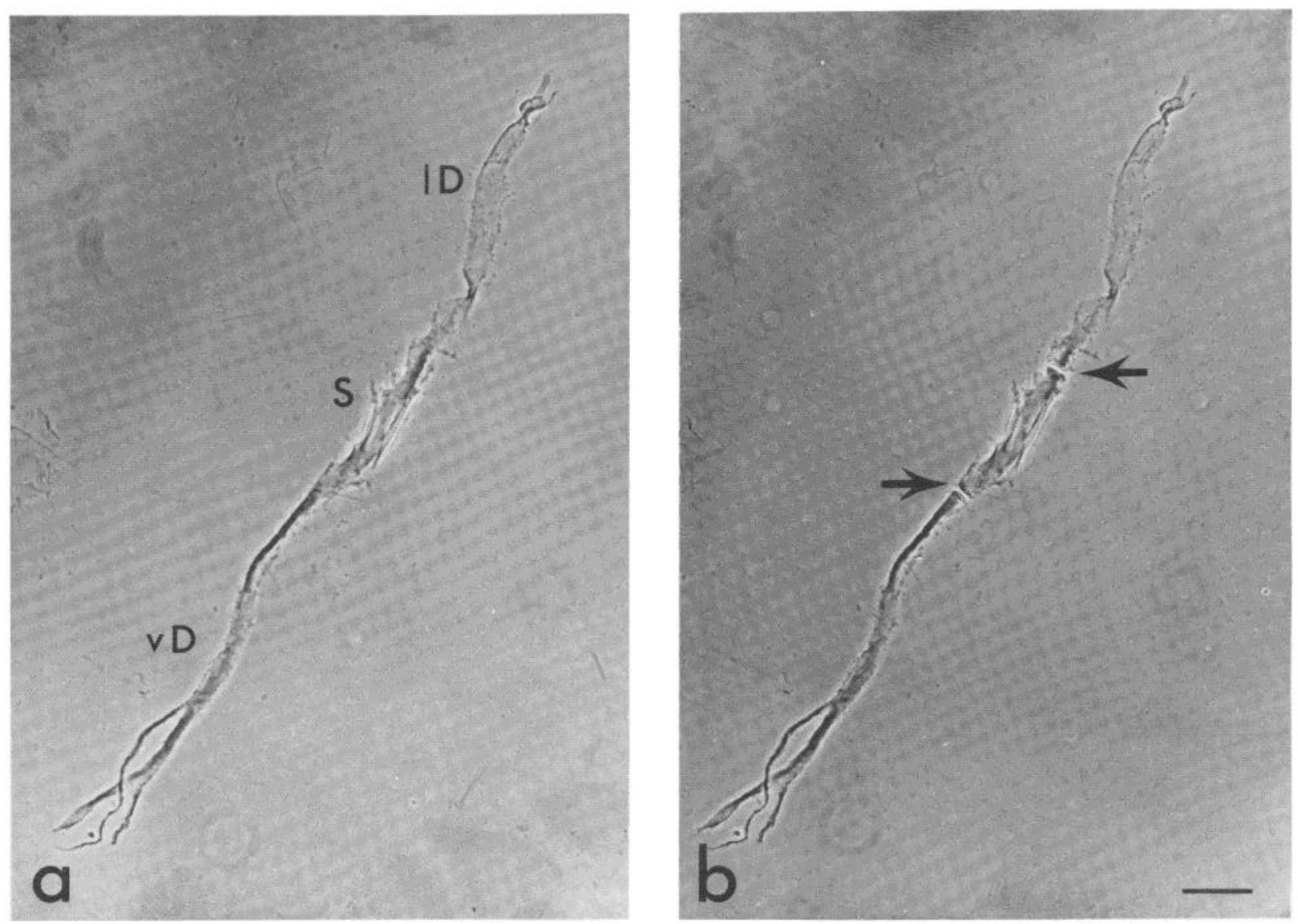

Figure 1. Isolated perikaryon of the Mauthner neuron (M-cell) in preparation for ultramicroelectrophoresis. $a$ and $b$ represent phase-contrast photomicrographs of a Mauthner cell before and after severing the lateral $(I D)$ and ventral $(v D)$ dendrites from the soma $(S)$, respectively, in preparation for separate solubilization and ultramicroelectrophoresis of soma and dendrites. Calibration bar, $0.1 \mathrm{~mm}$. 

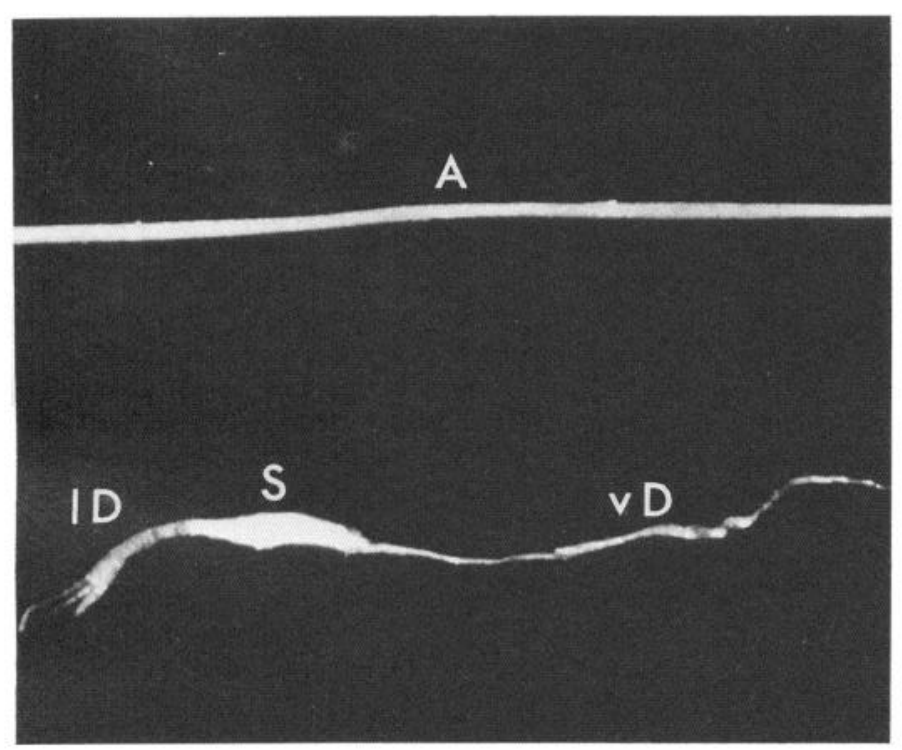

Figure 2. Isolated components of the Mauthner neuron in preparation for immunocytochemistry. A darkfield photomicrograph, taken through a dissecting microscope, of an isolated Mauthner cell perikaryon and desheathed axon $(A)$ in preparation for immunocytochemistry is shown. Abbreviations are as in Figure 1. Calibration $=0.1 \mathrm{~mm}$.

was diluted with two parts $0.5 \%$ Triton X-100 in TM buffer and applied to the samples for $1 \mathrm{hr}$ at room temperature. The samples were washed for a minimum of 30 min with a minimum of three washes and then incubated for $30 \mathrm{~min}$ at room temperature with fluorescein-conjugated goat anti-rabbit lgG (Sigma), diluted 1:150 with TM buffer. Coverslips were mounted in Elvanol (Rodriguez and Reinhardt, 1968) at this juncture or were further processed for labeling of $\mathrm{F}$-actin with rhodamine-conjugated phalloidin (Molecular Probes). In the latter instance, rhodamine-conjugated phalloidin was diluted 1:100 with TM buffer, and samples were incubated for $20 \mathrm{~min}$ at room temperature. After two washes the coverslip was mounted. Samples were viewed in a Zeiss fluorescence microscope equipped with phase-contrast optics and epifluorescence attachment. The double reflection sleeve in the latter attachment contained special combinations of exciter, beam splitter, and barrier filters for viewing fluorescein isothiocyanate and rhodamine fluorescence selectively.

\section{S tained}

\section{4}

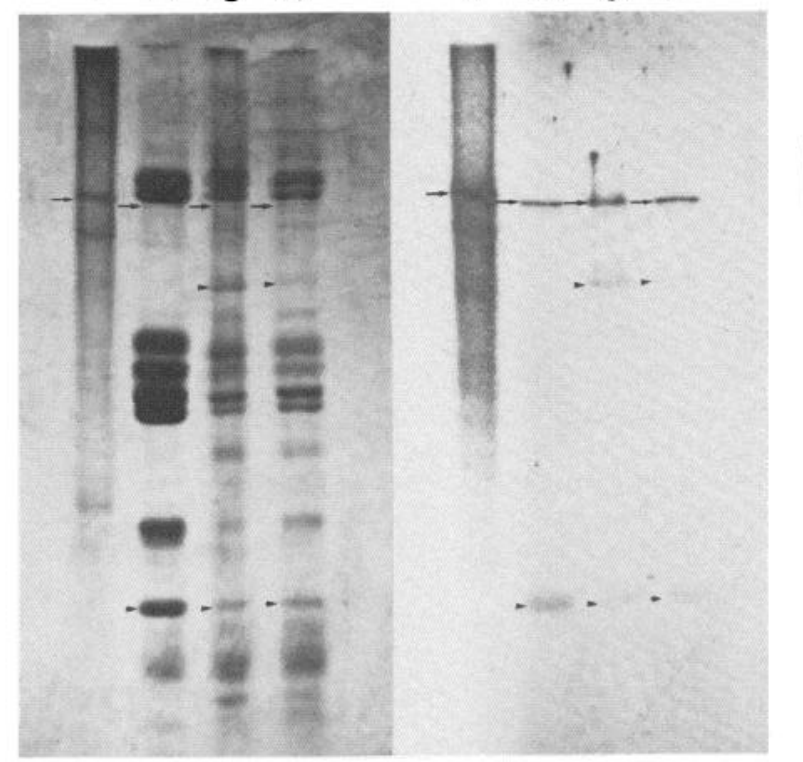

\section{Results}

Immunolabeling of gel microslabs. Figure 3 shows an immunoradiograph of a gel microslab containing a sample of chicken erythrocyte membrane proteins, separately pooled samples of somatic and dendritic proteins from two M-cells, and a sample of $M$ axon proteins. ${ }^{125}$-labeling is predominantly associated with a polypeptide that co-migrates with chicken erythrocyte $\alpha$-spectrin. In the M-cell, the putative $\alpha$-spectrin polypeptide can be masked by the slightly higher molecular weight doublet that is disproportionately enriched in the M-cell compared to other fish axons (see below). In this particular experiment (Fig. 3), very weak labeling was also associated with components that corresponded to a stained 180,000 -dalton band that appeared selectively distributed to the soma and dendrites, and a stained 62,000-dalton band, present in all three cellular subdivisions. It is unlikely that the weakly labeled bands represent degradation products of $\alpha$-spectrin because they are more prominent than the $\alpha$-spectrin band.

Figure 4 shows an immunoradiograph of a gel microslab in which the labeling patterns are compared between the $\mathrm{M}$-axon and other myelinated axons of the goldfish central nervous system and ventral root of the rabbit. Again, the antiserum cross-reacted with a polypeptide in all axons that co-migrated with chicken erythrocyte $\alpha$ spectrin. In addition, there was weak labeling of the 62,000-dalton component only in goldfish axons. It is of interest that a comparison of labeling intensity between the M-axon and other goldfish myelinated axons of Figure 4 (lanes 3 and 4 ) indicates that the proportional content of $\alpha$-spectrin in the large $\mathrm{M}$-axon is less than in smaller axons. This is further supported by a comparison of staining intensities of the spectrin dimer in microelectrophoretograms of the $M$ axon and other goldfish axons. Figure 5 is an enlargement of the spectrin region of a stained gel microslab. Whereas the $\alpha$-spectrin of the $\mathrm{M}$-axon is masked by the faster moving member of a high molecular weight doublet enriched in this particular axon, it is clear from a comparison of the equilmolar smaller spectrin subunit (i.e., $\beta$-fodrin, according to Carlin et al., 1983; brain-specific $\gamma$-spectrin according to Lazarides and Nelson, 1983) that the spectrin content is greater in smaller axons. The diameter of the desheathed $\mathrm{M}$-axon in the rostral neuraxis ranges from 40 to $80 \mu \mathrm{m}$ (Funch et al., 1981), whereas other axons of the goldfish have diameters probably well
Figure 3. Immunolabeling of $\alpha$-spectrin in a gel microslab after SDS ultramicroelectrohoresis of cellular components of the Mauthner neuron. Samples are as follows: lane 1, crude chicken erythrocyte membrane fraction; lane 2, desheathed M-cell axon; lane 3, M-cell soma; lane 4, M-cell dendrites. Arrows indicate the $\alpha$-spectrin band; arrowheads indicate other bands (i.e., 180,000 and 62,000) that cross-reacted with antiserum. The calibration bar indicates the distance over which polypeptides were separated. 
Figure 4. Immunolabeling of $\alpha$-spectrin in a gel microslab after SDS ultramicroelectrophoresis of desheathed axons. Samples are as follows: lane 1, crude chicken erythrocyte membrane fraction; lane 2, desheathed axons from rabbit ventral root; lane 3, desheathed axons from goldfish spinal cord; lane 4, desheathed $M$ cell axon. Arrows indicate the $\alpha$-spectrin band; arrowheads indicate the 62,000 -dalton band that cross-reacted with antiserum. The calibration bar indicates the distance over which polypeptides were separated.

Figure 5. A comparison of spectrin polypeptides in selected axons, showing an enlargement of the spectrin-containing region of a gel microslab. Samples are as follows: lane 1 . crude chicken erythrocyte membrane fraction; lane 2 , desheathed M-cell axon; lane 3, desheathed axons from goldfish spinal cord; lane 4, desheathed axons from rabbit ventral root. The upper arrows indicate the location of $\alpha$ spectrin bands (masked in the M-axon by a 245,000 -daltons major polypeptide which is a minor component in other goldfish axons; cf. lanes 2 and 3); the lower arrows indicate $\gamma$-spectrin ( $\beta$-fodrin). The calibration bar indicates the distance over which polypeptides were separated.

\section{S t a i ned}

$\begin{array}{llllllll}1 & 2 & 3 & 4 & 1 & 2 & 3 & 4\end{array}$

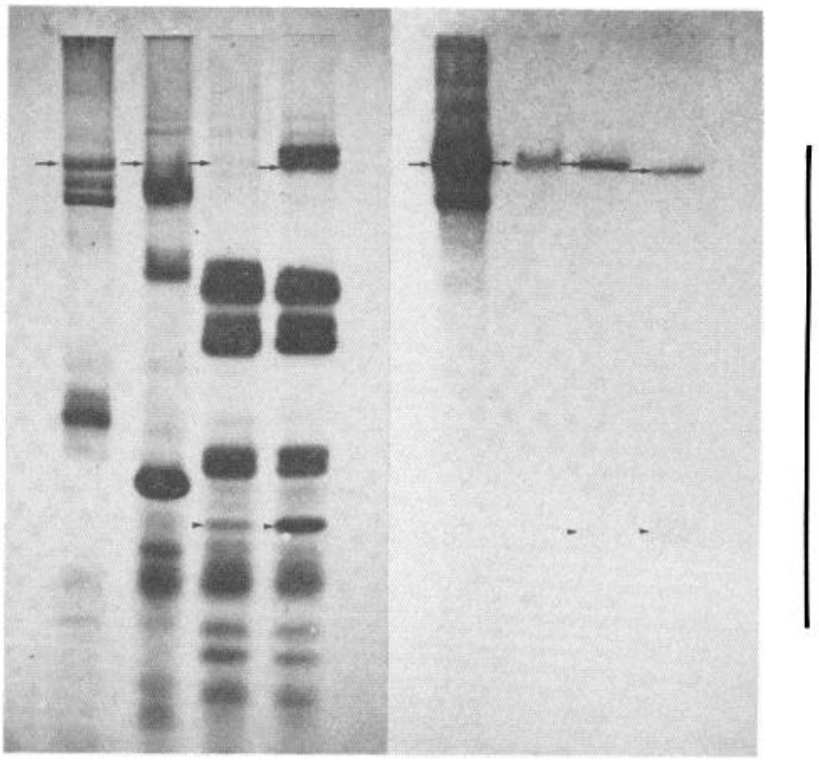

$1 \mathrm{~cm}$
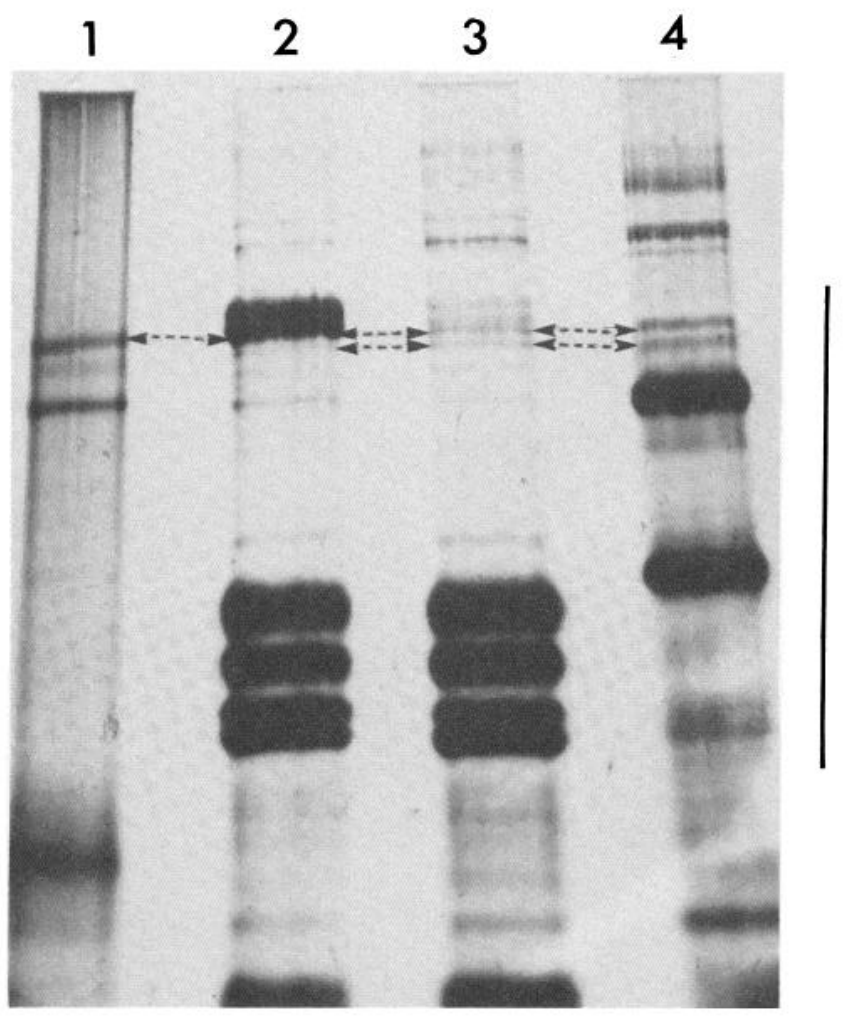

$0.5 \mathrm{~cm}$

below $20 \mu \mathrm{m}$. These differences are consistent with the assumption that spectrin is distributed predominantly near the surface of the axon because the larger axon has a smaller surface-to-volume ratio. The conclusion related to surface localization is further supported by immunocytochemical experiments (see below).

Indirect immunofluorescence of $\alpha$-spectrin is shown in Figure 6. The pattern is typically that of an irregular, randomly distributed reticular network, visible only when the microscopic plane of focus is at the surface (Fig. 6a), but not visible within the interior of the Maxon (Fig. 6c).

The $\mathrm{M}$-axon is atypical of myelinated axons because there are no nodal gaps that ordinarily interrupt the myelin sheath (i.e., myelin sheath is structurally continuous), and there are no visible specializations of the axon that correspond to nodes of Ranvier, although functional nodes have been identified (Funch and Faber, 1982). Indeed, other goldfish CNS axons isolated from their myelin sheaths also do not exhibit morphological nodal specializations that characterize mammalian nodes of Ranvier, the presence of nodal gaps in their myelin sheath notwithstanding. For this reason axons from rabbit ventral roots were used to examine spectrin immunofluorescence at nodes of Ranvier.

Nodes of Ranvier are very easily identified by inspection of 

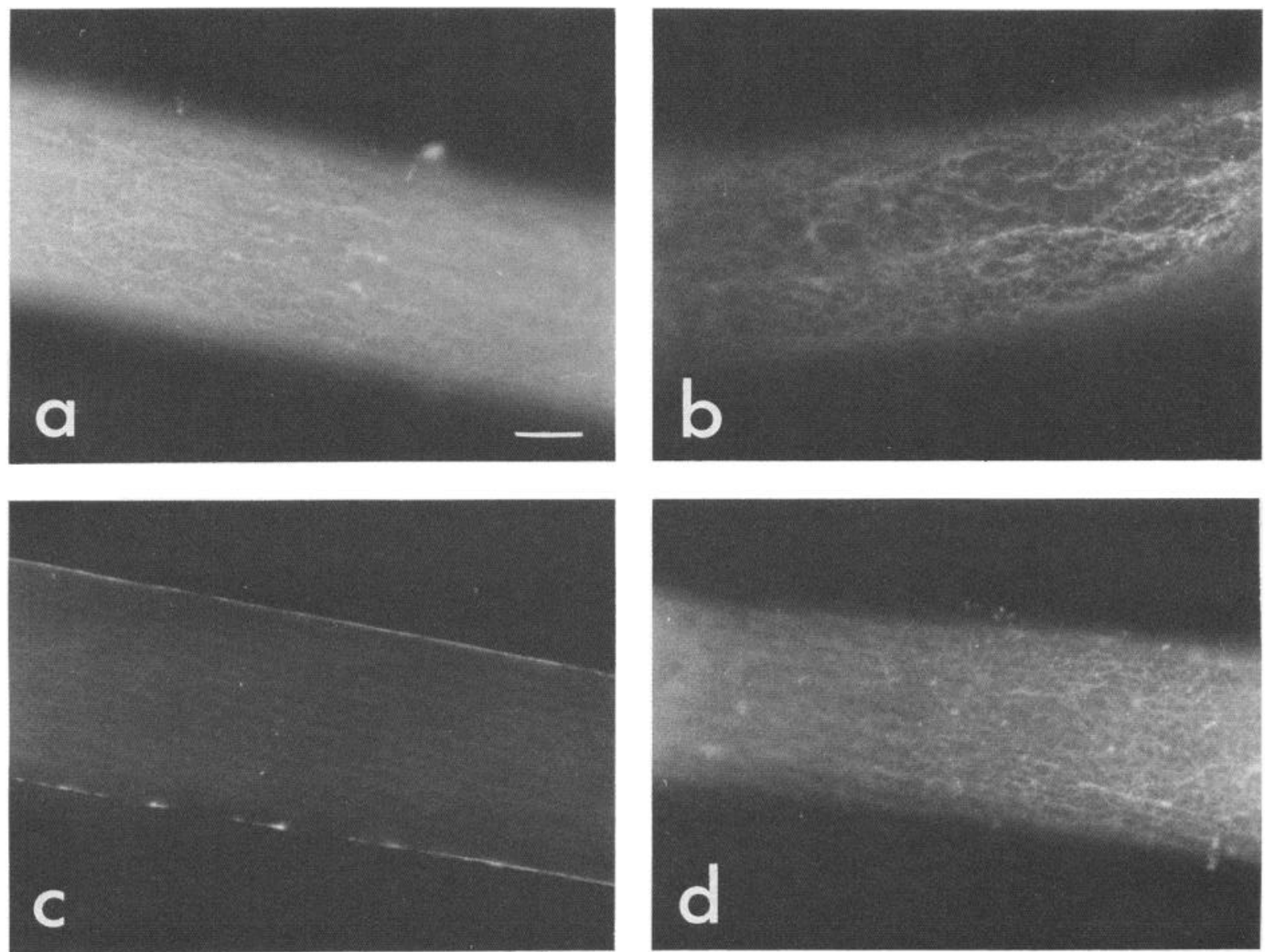

Figure 6. Immunofluorescence localization of $\alpha$-spectrin in desheathed M-cell axons. $a, b$, and $d$ are three different preparations in which the plane of focus was at the axon's surface; $c$ is the same axon shown in $a$, in which the plane of focus was within the axon's interior. Calibration bar, $10 \mu \mathrm{m}$.

mammalian axons isolated from their myelin sheaths under phasecontrast microscopy. Typically, although not invariably, the caliber of the myelin-free axon is significantly reduced; i.e., there is a constriction at nodes of Ranvier, with the region of maximum constriction having a diameter a little more than half of that of the internodal axon. However, the midpoint of the constriction exhibits a circumscribed increase in axon diameter, which usually corresponds to a phase-dense circumferential band or nub (Fig. 7, a to c). Strictly speaking, the band or nub actually constitutes the node of Ranvier, and the paranodal constriction on either side constitutes the region of myelin sheath attachment and is referred to as the myelin sheath attachment segment (Berthold, 1978). Figure 7 shows that $\alpha$-spectrin immunofluorescence is most intense at nodes of Ranvier, where it appears to be associated with a phase-dense circumferential band or nub. At this location, the distribution is nonrandom; elsewhere, (i.e., the internode), the immunofluorescent pattern is similar to that of the $\mathrm{M}$-axon (not shown); i.e., the $\alpha$ spectrin network appears randomly distributed at the axons's surface.

In the soma and dendrites of the M-cell, $\alpha$-spectrin has both random and nonrandom distributions. The latter distribution is associated with what appear from fluorescent images to be synapses (Fig. 8). On the distal lateral dendrite of the M-cell (Figs. 1 and 2), the fluorescence images of putative synapses are unusually large and prominent, measuring several micrometers across (Fig. 9). This distribution and the size of the image profiles are consistent with their being associated with terminals identified as large myelinated club endings from the ipsilateral VIIIth nerve (Bodian, 1937; Nakajima and Kohno, 1978). Inspection of immunofluorescence images of the putative synapses show a nonuniform, fenestrated structure; i.e., foci of variable size where there is an absence of immunofluorescence (Fig. 9). Large club endings are known to form mixed synapses, where both chemical and electrical transmission occurs (for review, see Faber and Korn, 1978; Lin and Faber, 1983). It is unlikely, however, that the putative synaptic structures represent only postsynaptic densities (see "Discussion").

Erythrocyte spectrin and brain spectrin (fodrin) have been shown in vitro to be F-actin-binding proteins and presumably serve to crosslink oligomeric segments of actin in vivo (Brenner and Korn, 1979; Levine and Willard, 1981; Burridge et al., 1982; Glenny et al., 1982a, b). We have attempted to conduct double labeling experiments in order to investigate whether there is any correspondence between the localization of F-actin and $\alpha$-spectrin. In these experiments, rhodamine-conjugated phalloidin was used to label F-actin and fluorescein for indirect labeling of $\alpha$-spectrin. Figure 9 shows typical examples of such an experiment in which there is a striking correspondence of fluorescein and rhodamine fluorescence images due to labeling of large myelinated club ending synapses. A similar correspondence can be seen at nodes of Ranvier in rabbit axons (Fig. 7c). The lower background of rhodamine fluorescence in the paranodal myelin attachment segment is favorable for discerning an actin-spectrin co-localization at the node of Ranvier. In the internode, however, background rhodamine-phalloidin fluorescence makes it difficult to discern a surface spectrin-actin network, although under favorable circumstances it can be discerned. Although the filter systems used were selective for fluorescein or rhodamine fluorescence, we have confirmed a similar nonrandom localization of $F$ actin and $\alpha$-spectrin fluorescence in separate experiments with single labeling. 

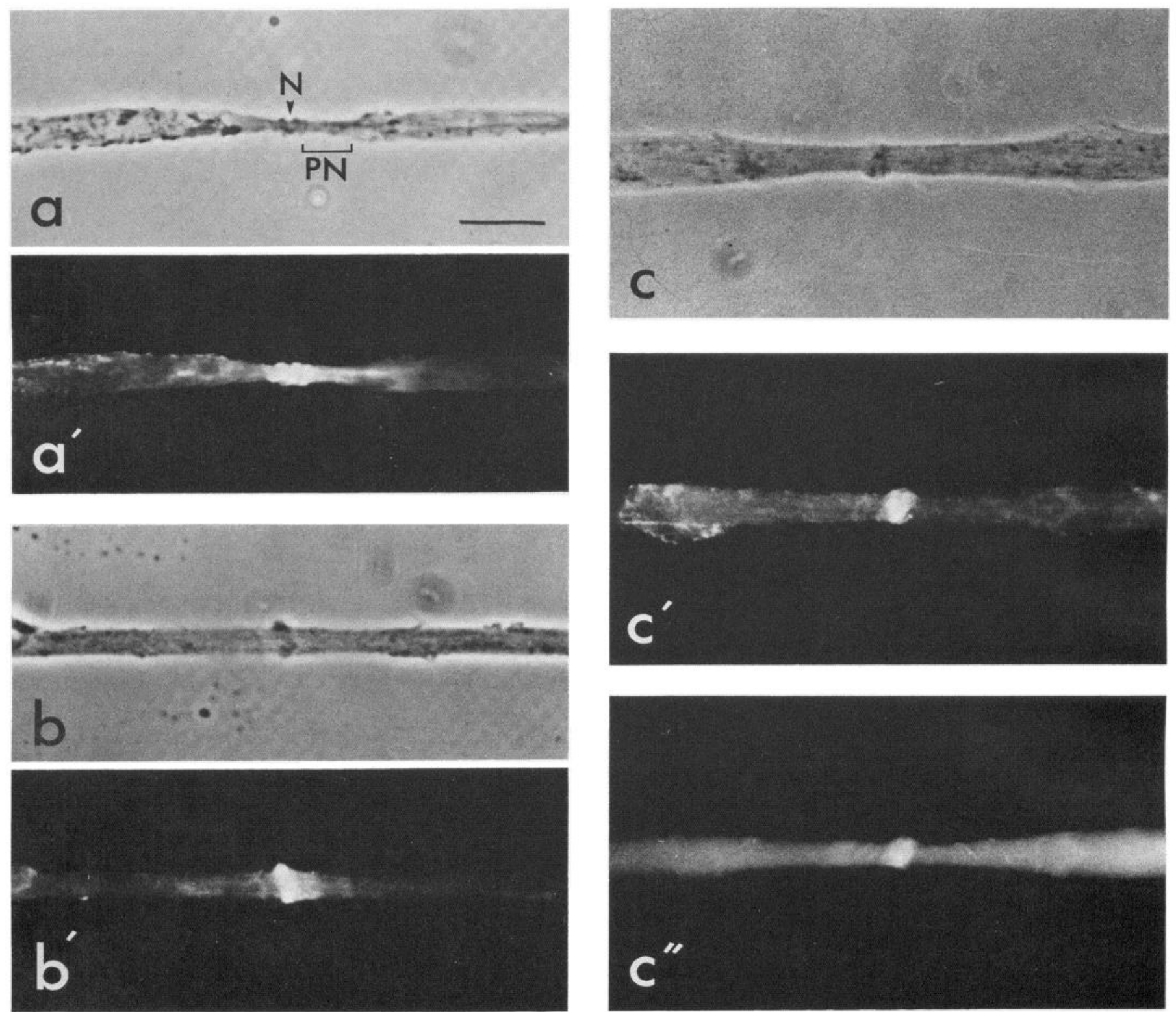

Figure 7. Localization of $\alpha$-spectrin and F-actin at nodes of Ranvier in desheathed rabbit ventral root axons. $a, b$, and $c$ are phase-contrast photomicrographs of three different axonal preparations; $a^{\prime}, b^{\prime}$, and $c^{\prime}$ are $\alpha$-spectrin fluorescein immunofluorescence photographs; and $c^{\prime \prime}$ is a rhodamine fluorescence photograph due to secondary labeling with phalloidin. $N$, node of Ranvier; PN, paranode. Calibration bar, $10 \mu \mathrm{m}$.

\section{Discussion}

The chicken erythrocyte $\alpha$-spectrin antiserum used in the present investigation was shown by immunofluorescence microscopy in a previous study to cross-react with CNS and PNS neurons of the chicken (Repasky et al., 1982). In the present study, we have focused largely on a particular identifiable neuron, the Mauthner cell (M-cell) of the goldfish. Its size, its simple morphology, and its accessibility for isolation by microdissection make it a favorable preparation for analytical studies on a microscale. In addition, a good deal of information is known about the topography of the afferents terminating on the cell.

Polyacrylamide gel microslabs, containing separate samples of dendritic, somatic, and axonal proteins of the M-cell, as well as other axons of the goldfish and rabbit, revealed that there was a polypeptide that co-migrated with chicken erythrocyte $\alpha$-spectrin and crossreacted with the spectrin antiserum. These results provide direct immunochemical evidence at a cellular level that a spectrin-like protein is associated with neurons of the goldfish and rabbit. This finding confirms similar immunochemical results based on fraction- ated brain tissue extracts (Levine and Willard, 1981; Bennett et al., 1982a; Burridge et al., 1982; Glenny et al., 1982b; Kakiuchi et al., 1982; Palfrey et al., 1982; Repasky et al., 1982; Carlin et al., 1983).

Hand-isolated cellular preparations for imunocytochemical studies have the advantage of revealing distributional and organizational features that cannot be easily appreciated using standard histological sectioning techniques. In such preparations, $\alpha$-spectrin immunofluorescence generally appears as an irregular reticular network, localized near the cell's surface, and is distributed in an apparent random manner throughout the neuron, with certain notable exceptions (see below).

Whether the foregoing characterization, based on the typical immunofluorescence picture, reflects an authentic in vivo distributional organization of the spectrin network in the axon is a moot question, nonetheless. The technique of translating the axon out of its myelin sheath imposes a longitudinal mechanical strain that could alter significantly the network's organizational pattern because the axon behaves as an elastic solid. Thus, stretching could cause random breakage of the meshwork and could result in local aggre- 

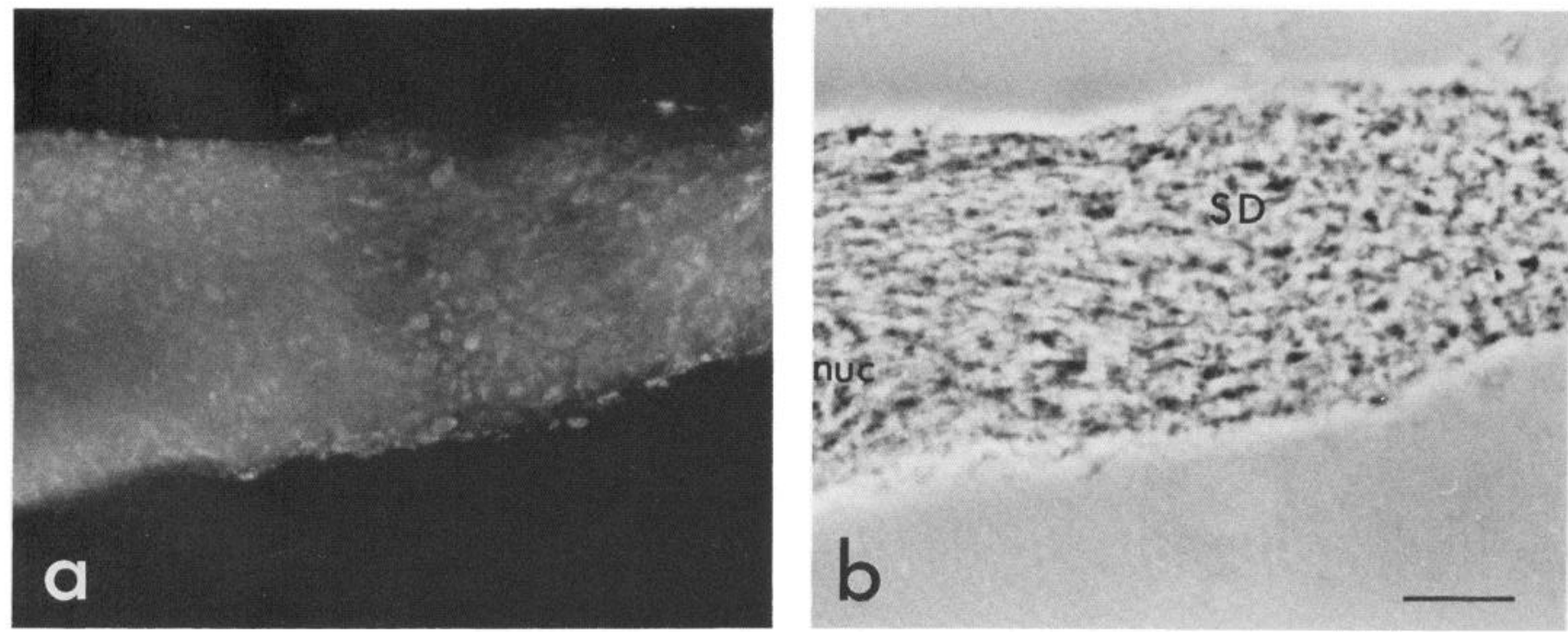

Figure 8. Localization of $\alpha$-spectrin at the surface of the isolated M-cell perikaryon. a shows the distribution of $\alpha$-spectrin based on immunofluorescence, located at the surface of the soma-dendrite region of an M-cell. $b$ is a phase-contrast photomicrograph of the cell shown in $a$. Immunofluorescence appears to be associated with synapses. nuc, nucleus; $S D$, soma-dendrite transition zone. Calibration bar, $10 \mu \mathrm{m}$.

gation that would probably reveal itself as a coarse, irregular mesh. When compliance of the axon is markedly reduced by increasing the zinc concentration in the isolating medium (e.g., $0.1 \mathrm{M}$ zinc), the typical organizational pattern does not appear to be changed sig nificantly.

Evidence that spectrin is largely localized near the surface is based on both immunochemical and immunofluorescence findings. First, in the large $\mathrm{M}$-axon, which is 4 to 5 times larger in diameter than ordinary "large" axons, the spectrin network is visible only when the plane of focus is at the surface of the axon and not when it is in the interior. Second, the $\alpha$-spectrin polypeptide of ordinary goldfish axons in gel microslabs is 'more heavily labeled than is the case for the $\mathrm{M}$-axon. Also consistent with this quantitative difference is that inspection of stained gel microslabs indicates that smaller axons have proportionately more spectrin than does the $\mathrm{M}$-axon for equivalent sample loadings. If spectrin is localized primarily at the axon's perimeter, then the higher proportional content of spectrin in smaller axons can be explained by their larger surface-to-volume ratio.

In a study of axoplasmic structure, using the rapidly frozen and etched axons of the turtle optic nerve, Schnapp and Reese (1982) described a $100-\mathrm{nm}$ subaxolemmal zone, representing a special domain that is distinguishable from neurofilament and microtubule domains. These authors further described filamentous material, unlike that observed in the other axoplasmic domains, spanning the space between bordering neurofilaments, to which it is attached, and the inner surface of the axolemma where it is linked to some 8to 9 -nm particles. A subaxolemmal filamentous meshwork has also been described recently in a freeze-etch study of the rat trigeminal nerve (Tsukita et al., 1982). Although the filamentous material has not been characterized, it may correspond to the spectrin network which has been described in the present study and is presumably analogous to the spectrin-actin network associated with the erythrocyte membrane (Hainfeld and Steck, 1977; Branton et al., 1981; Bennett, 1982)

In addition to its apparent random distribution, $\alpha$-spectrin immunofluorescence is distributed nonrandomly in certain cases. The nonrandom distribution is localized at specialized cellular sites, such as synapses and nodes of Ranvier in axons that exhibit morphological nodal specializations (i.e., in rabbit, but not in goldfish axons). The localization of spectrin to synaptic sites by immunofluorescence is consistent with recent immunochemical evidence based on detergent-extracted synaptosome fractions, in which fodrin (spectrin) was shown to be a major component (Carlin et al., 1983; Hesketh et al., 1983). Rotary shadowing of isolated brain spectrin heterodimers indicates a maximum width dimension of 4 to $6 \mathrm{~nm}$ (Bennett et al., 1982a, b), and this dimension is similar to that of a class of filaments localized to postsynaptic densities (Gulley and Reese, 1981).

It is at synaptic sites of spectrin localization that a co-localization with F-actin, as revealed by rhodamine-phalloidin binding, can be demonstrated, as indicated by the correspondence of rhodamine and fluorescein fluorescence images. These results are consistent with several reports of actin being associated with postsynaptic densities (Blomberg et al., 1977; Kelly and Cotman, 1978; Matus et al., 1982; Hesketh et al., 1983). Since erythrocyte spectrin is an Factin-binding protein (Brenner and Korn, 1979, 1980), as is the case with brain spectrin (fodrin, calspectrin) (Levine and Willard, 1981; Burridge et al., 1982; Glenny et al., 1982b; Sobue et al., 1982), it appears likely that the F-actin, visualized by phalloidin fluorescence, and spectrin represent a spectrin-actin network.

However, from what is known about the localization of postsynaptic densities at the large myelinated club ending synapse, it is clear that the distribution of fluorescence does not correspond to the distribution of postsynaptic densities. This synapse has a complex morphology insofar as it contains specializations related to both chemical and electrical transmission (Nakajima and Kohno, 1978). According to Tuttle et al. (1983), multiple chemical "active zones" are distributed presynaptically around the periphery of large myelinated club endings, whereas gap junctions are more centrally located. Compact postsynaptic densities associated with unmyelinated and myelinated club endings are circumscribed and delimited by boundaries defined by the presynaptic vesicular grid (i.e., active zones) with which the postsynaptic density is in direct apposition (Triller and Korn, 1982; Wood and Faber, 1983). If the labeling is restricted only to compact postsynaptic densities, then the pattern of fluorescence should correspond to a circumferential distribution of discrete fluorescent foci located at the periphery of the synaptic junction. Since this is not the case, it appears that the distributions of $\alpha$ spectrin and actin at synaptic junctions are not restricted to compact postsynaptic densities. An example of this particular synapse is shown in cross-section at the electron microscopic level in Figure 10 (kindly provided by Dr. Malcolm R. Wood). In addition, there are diffuse junctional densities associated with puncta adherentia and gap junctions that are distributed in regions adjacent to compact postsynaptic densities (also, cf. Fig. 2c in Wood and Faber, 1983). In conclusion, these findings suggest that a spectrin-actin network 

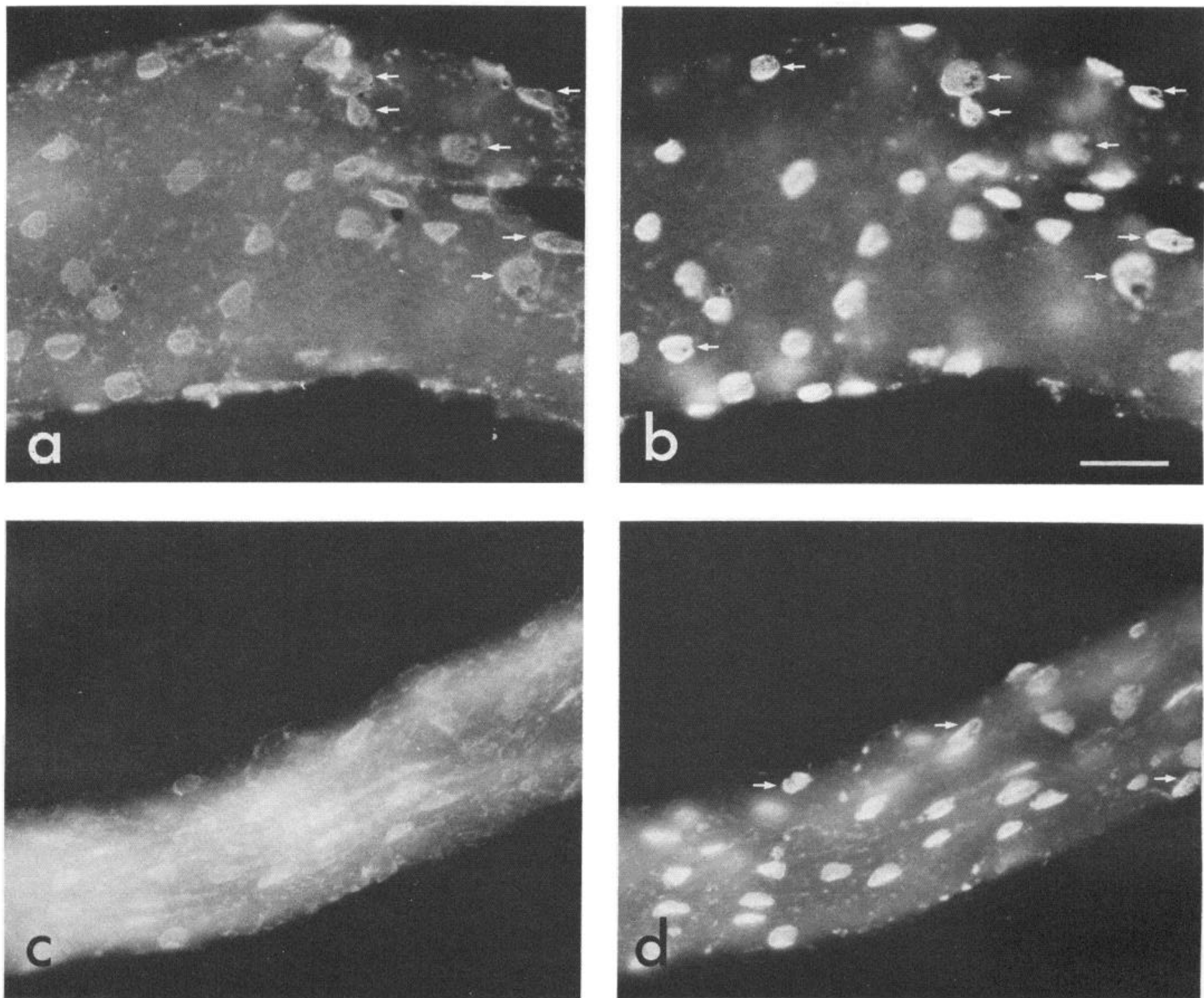

Figure 9. Co-localization of $\alpha$-spectrin and F-actin in large myelinated club ending synapses on the lateral dendrite of the M-cell. a and $c$ are fluorescein $\alpha$-spectrin immunofluorescence images; $b$ and $d$ are corresponding rhodamine fluorescence images due to phalloidin binding (in $b$, the plane of focus is slightly below that of a). Note fenestrations in favorably oriented synaptic junctional profiles (arrows). Calibration bar, $10 \mu \mathrm{m}$.

is associated with the whole area of junctional contact, and that the nonuniform distribution of fluorescence, as reflected by fenestrations of varying size, may correspond to discontinuities interspersed between zones of diffuse and compact postsynaptic densities.

In the axon, nodes of Ranvier are another site where there is a co-localization of $\alpha$-spectrin and F-actin, as indicated by double labeling experiments. In the internode, a high background phalloidin fluorescence tends to obscure specialized surface structures.

The function of the subplasmalemmal spectrin-cytoskeletal network is only partially understood. In the erythrocyte it appears to play a role in anchoring a certain fraction of membrane anion channel protein (i.e., band 3; see Bennett, 1982), but the network is also important for mechanically stabilizing the membrane (Marchesi, 1979; Fischer et al., 1978; Branton et al., 1981; Gretzer, 1981). In contrast, in certain nonerythroid cells, it appears to have motile functions related to membranes. For example, in fibroblasts and lymphocytes, it appears to be associated with the process of membrane receptor capping (Levine and Willard, 1983; Nelson et al., 1983). In the axon, it undergoes axoplasmic transport (Lorenz and Willard, 1978), where it has been suggested that it may be involved in the transport of protein and organelles moving in transport groups II, III, IV, and V (Levine and Willard, 1981, 1983).

The latter proposal by Levine and Willard $(1981,1983)$ is consistent with observations made in this laboratory, where $\alpha$-spectrin and actin have been shown to be associated with mobile structures of growing axons produced by goldfish retinal explants (Koenig, et al., 1983, 1985). The mobile structures consist of large varicosities and small, phase-dense inclusions which undergo rapid and very rapid saltations, respectively. These structures contain aggregations of tubulovesicular endoplasmic reticulum, and we have concluded that they represent a mode by which "packaged" cytomembranes undergo rapid bulk transport in these particular axons (Koenig et al., 1983, 1984). We have suggested, therefore, that the co-transport of spectrin and actin with cytomembranes may reflect roles in the bulk "packaging" and transport of cytomembranes destined for plasmalemma recycling.

Spectrin is a variant heterodimer, composed of a common, but nonidentical, $\alpha$-subunit $\left(M_{\mathrm{r}}=240,000\right)$ and a variant second subunit of differing molecular weights (i.e., $M_{\mathrm{r}}=260,000,235,000$, and 220,000 ) that may reflect cell-specific functions (Glenny et al., 


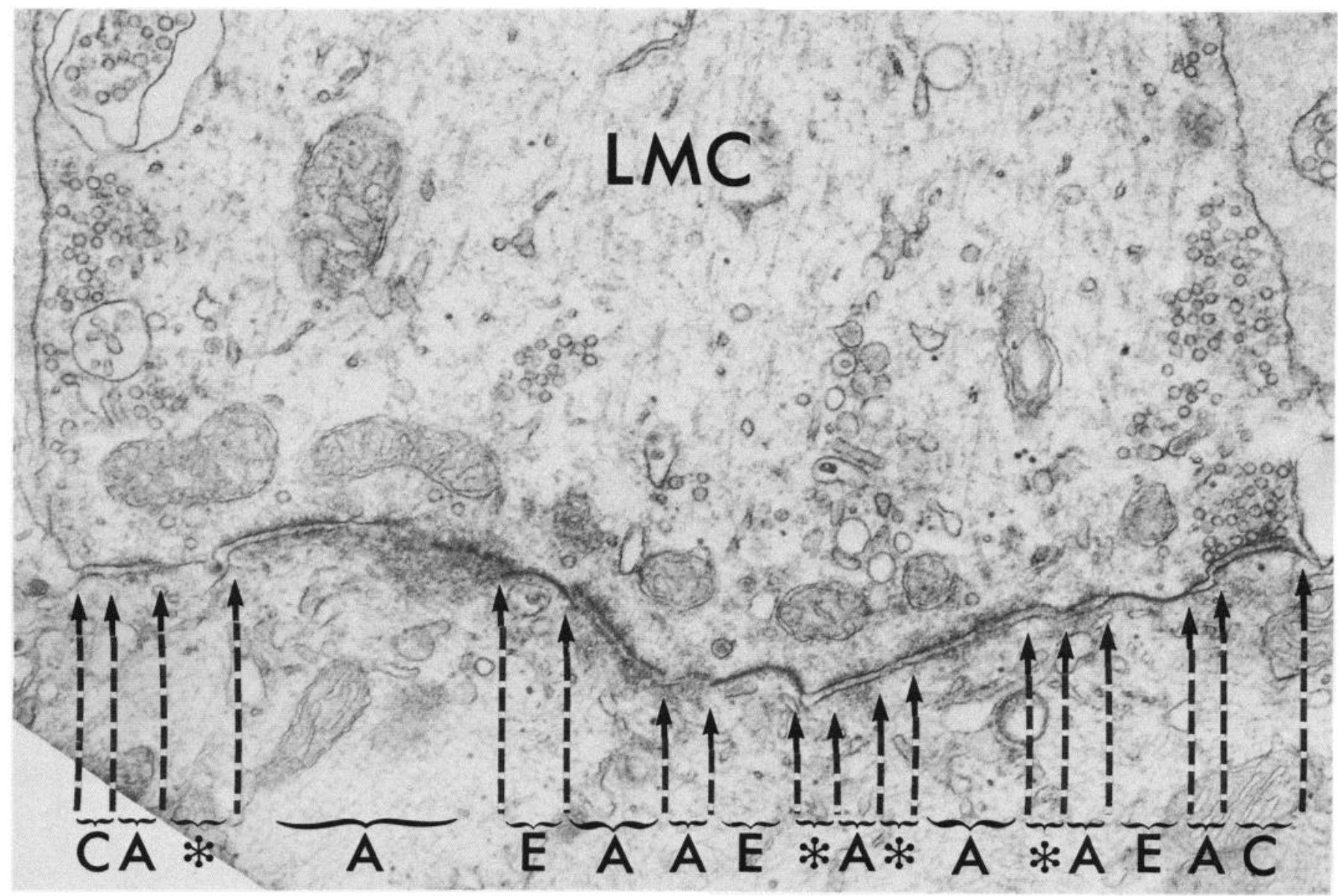

Figure 10. Electron micrograph of a large myelinated club ending $(L M C)$ on the lateral dendrite of the M-cell. The zone of synaptic contact exhibits three distinct junctional specializations: junctions related to chemical transmission $(C)$, electrical transmission $(E)$, and puncta adherentia $(A)$, each of which is associated with either diffuse or compact densities on the postsynaptic side. Interspersed between junctional specializations are circumscribed foci that lack any apparent density $(*)$. The latter may correspond to "fenestrations" present in junctional patterns of fluorescence related to spectrin and F-actin distributions (cf. Fig. 9). Magnification $\times$ 43,700 (courtesy of Dr. Malcolm R. Wood).

1982a). In erythrocytes, where anchorage of the anion channel protein appears to be an important function (see above), the 220,000 -dalton $\beta$-chain is attached to band 3 through ankyrin (see Bennett, 1982). Where it functions in motility-related behavior (e.g., axoplasmic transport, membrane receptor capping), the heterodimer appears to be composed of an $\alpha$-subunit and the brain form of the $\beta$-subunit (Levine and Willard, 1981; Nelson et al., 1983). Because both erythrocyte and brain spectrins contain ankyrin- and actinbinding sites (Bennett et al., 1982a), it is possible that the apparent distinction in functions associated with the $\beta$-subunit may relate to the presence or absence of a property that directly or indirectly governs interaction with a force-generating system. In this context, it is worth noting that the erythrocyte form of $\beta$-spectrin is expressed in retinal ganglion cells during synaptogenesis (Lazarides et al., 1984) and is apparently limited in distribution to cell bodies and dendrites of cerebellar neurons (Lazarides and Nelson, 1983). It would be of interest to ascertain whether the latter distribution is restricted to synaptic junctional complexes and perhaps to other specialized cellular sites requiring relative immobility of membrane receptors and/or channels, such as at the initial segment and nodes of Ranvier of the axon. Thus, the presence of both brain and erythrocyte forms of spectrin subunits in the same cell would be consistent with a duality of roles for spectrin related to intracellular motility and anchorage functions associated with plasma membrane and possibly their precursors.

\section{References}

Bennett, V. (1982) The molecular basis for membrane cytoskeleton association in human erythrocytes. J. Cell. Biochem. 18: 49-65.
Bennett, V., J. Davis, and W. E. Fowler (1982a) Immunoreactive forms of erythrocyte spectrin and ankyrin in brain. Philos. Trans. R. Soc. Lond. (Biol.) 299: 301-312.

Bennett, V., J. Davis, and W. E. Fowler (1982b) Brain spectrin, membraneassociated protein related in structure and function to erythrocyte spectrin. Nature 299: 126-131.

Berthold, C. -H. (1978) Morphology of normal peripheral axons. In Physiology and Pathobiology of Axons, S. G. Waxman, ed., pp. 3-63, Raven Press, New York.

Blomberg, F., R. S. Cohen, and P. Siekewitz (1977) The structure of post synaptic densities isolated from dog cerebral cortex. II. Characterization and arrangement of some major proteins within the structure. J. Cell Biol. 74: 204-225.

Bodian, D. (1937) The structure of the vertebrate synapse. A study of the axon endings on Mauthner's cell and neighboring centers in the goldfish. J. Comp. Neurol. 68: 117-159.

Branton, D., C. M. Cohen, and J. Tyler (1981) Interaction of cytoskeletal proteins in the human erythrocyte membrane. Cell 24: 24-32.

Brenner, S. L., and E. D. Korn (1979) Spectrin-actin interaction. J. Biol. Chem. 254: 8620-8627.

Brenner, S. L., and E. D. Korn (1980) Spectrin/actin complex isolated from sheep erythrocytes accelerates actin polymerization by simple nucleation. J. Biol. Chem. 255: 1670-1676.

Burridge, K. (1978) Direct identification of specific glycoproteins and antigens in sodium dodecyl sulfate gels. Methods Enzymol. 50: 54-64.

Burridge, K., T. Kelly, and P. Mangeat (1982) Nonerythrocyte spectrins: Actinmembrane attachment proteins occurring in many cell types. J. Cell Biol. 95: 478-486.

Carlin, R. K., D. C. Bartelt, and P. Siekevitz (1983) Identification of fodrin as 
a major calmodulin-binding protein in postsynaptic density preparations. J. Cell Biol. 96: 443-448.

Clarke, M. (1971) Isolation and characterization of a water-soluble protein from bovine erythrocyte membrane. Biochem. Biophys. Res. Commun. 45: 1063-1070.

Faber, D. S., and H. Korn (1978) Electrophysiology of the Mauthner cell: Basic properties, synaptic mechanisms, and associated networks. In Neurobiology of the Mauthner Cell, D. S. Faber and H. Korn, eds., pp. 47-131, Raven Press, New York.

Fairbanks, G., T. G. Sherk, and D. F. H. Wallach (1971) Electrophoretic analysis of the major polypeptides of the human erythrocyte membrane. Biochemistry 10: 2607-2617.

Fischer, T. M., C. W. M. Haest, M. Stohr, D. Kamp, and B. Deutiche (1978) Selective alteration of erythrocyte deformability by SH-reagents: Evidence for an involvement of spectrin in membrane shear elasticity. Biochim. Biophys. Acta 510: 270-282.

Funch, P. G., and D. S. Faber (1982) Action-potential propagation and orthodromic impulse initiation in Mauthner axon. J. Neurophysiol. 47: 12141231.

Funch, P. G., S. L. Kinsman, D. S. Faber, E. Koenig, and S. J. Zottoli (1981) Mauthner axon diameter and impulse conduction velocity decrease with growth of goldfish. Neurosci. Lett. 27: 159-164.

Glenney, J. R., Jr., P. Glenney, and K. Weber (1982a) Erythroid spectrin brain fodrin and intestinal bruch border proteins (TW-240/260) are related molecules containing a common calmodulin-binding subunit bound to a variant cell type-specific subunit. Proc. Natl. Acad. Sci. U. S. A. 79: 40024005.

Glenney, J. R., Jr., P. Glenney, and K. Weber (1982b) F-actin-binding and cross-linking properties of porcine brain fodrin, a spectrin-related molecule. J. Biol. Chem. 257: 9781-9787

Goodman, S. R., I. S. Zagon, and R. R. Kulikowski (1981) Identification of a spectrin-like protein in nonerythroid cells. Proc. Natl. Acad. Sci. U. S. A. 78: 7570-7574.

Granger, B. L., and E. Lazarides (1980) Synemin: A new high molecular weight protein associated with lesmin and vimentin filaments in muscle. Cell 22: 727-738.

Greitzer, W. B. (1981) The red cell membrane and its cytoskeleton. Biochem. J. 198: 1-8.

Gulley, R. L., and T. S. Reese (1981) Cytoskeletal organization at the postsynaptic complex. J. Cell Biol. 91: 298-302.

Hainfeld, J. F., and T. L. Steck (1977) The sub-membrane reticulum of the human erythrocyte: A scanning electron microscope study. J. Supramol. Struct. 6: 3301-3311.

Hesketh, J. E., D. Thiersem, and D. Aunis (1983) Evidence for a spectrin-like protein as a major component of the synaptosomal membrane cytoskeleton. Biochem. Biophys. Res. Commun. 115: 437-443.

Hiller, G. and K. Weber (1977) Spectrin is absent in various tissue culture cells. Nature 266: $181-183$.

Kakiuchi, S., K. Sobue, K. Kanda, K. Morimoto, S. Tsukita, H. Ishikawa, and M. Kurokawa (1982) Correlative biochemical and morphological studies of brain calspectrin: A spectrin-like calmodulin-binding protein. Biomed. Res. 3: $400-410$

Kelly, P. T., and C. W. Cotman (1978) Characterization of tubulin and actin and identification of a distinct postsynaptic density polypeptide. J. Cell Biol. 79: 173-183.

Koenig, E. (1965) Synthetic mechanisms in the axon. II. RNA in myelin-free axons of the cat. J. Neurochem. 12: 357-361.

Koenig. E. (1978) Molecular biology of the Mauthner axon. In Neurobiology of the Mauthner Cell, D. S. Faber and H. Korn, eds., pp. 167-182, Raven Press, New York.

Kocnig, E., E. Repasky, and S. Kinsman (1983) Localization of $\alpha$-spectrin, actin and calmodulin to moving varicosities of growing axons. (Abstr.) $\mathrm{J}$. Neurochem. (Suppl.) 41: 595.

Koenig, E., S. Kinsman, E. Repasky, and L. Sultz (1985) Rapid mobility of motile varicosities and inclusions containing $\alpha$-spectrin, actin, and calmodulin in regenerating axons in vitro. J. Neurosci. 5: 715-729.

Lazarides, E., and W. J. Nelson (1983) Erythrocyte and brain forms of spectrin in cerebellum: Distinct membrane-cytoskeletal domains in neurons. Science 22: 1295-1296.

Lazarides, E., W. J. Nelson, and T. Kasamatsu (1984) Segregation of two spectrin forms in the chicken optic system: A mechanism for establishing restricted membrane-cytoskeletal domains in neurons. Cell 36: 269-278.

Levine, J., and M. Willard (1981) Fodrin: Axonally transported polypeptides associated with the internal periphery of many cells. J. Cell Biol. 90: 631643.

Levine, J., and M. Willard (1983) Redistribution of fodrin (a component of the cortical cytoplasm) accompanying capping of cell surface molecules. Proc. Natl. Acad. Sci. U. S. A. 80: 191-195.

Lorenz, T., and M. Willard (1978) Subcellular fractionation of intra-axonally transported polypeptides in the rabbit visual system. Proc. Natl. Acad. Sci. U. S. A. 75: 505-509

Marchesi, V. T. (1979) Spectrin: Present status of a putative cytoskeletal protein of the red cell membrane. J. Membr. Biol. 51: 101-131.

Marchesi, V. T., and E. Steers, Jr. (1968) Selective solubilization of a protein component of the red cell membrane. Science 159: 203.

Matus, A., M. Ackermann, G. Pehling, R. Byers, and K. Fujiwara (1982) High actin concentrations in brain dendritic spine and postsynaptic densities. Proc. Natl. Acad. Sci. U. S. A. 79: 7590-7594.

Nakajima, Y., and K. Kohno (1978) Fine structure of the Mauthner cell: Synaptic topography and comparative study. In Neurobiology of the Mauthner Cell, D. Faber and H. Korn, eds., pp. 133-166, Raven Press, New York.

Nelson, W. J., C. A. L. S. Colaco, and E. Lazarides (1983) Involvement of spectrin in cell-surface receptor capping in lymphocytes. Proc. Natl. Acad. Sci U. S. A. 80:1626-1630.

Painter, R. G., M. Sheetz, and S. S. Singer (1975) Detection and ultrastructural localization of human smooth muscle myosin-like molecules in human nonmuscle cells by specific antibodies. Proc. Natl. Acad. Sci. U. S. A. 72: 1359-1363.

Paltrey, H. G., W. Schiebler, and P. Greengard (1982) A major calmodulin binding protein common to various vertebrate tissues. Proc. Natl. Acad. Sci. U. S. A. 79: $3780-3784$

Repasky, E. A., B. L. Granger, and E. Lazarides (1982) Widespread occurrence of avian spectrin in nonerythroid cells. Cell 29: 821-833.

Rodriguez, T., and F. Reinhardt (1968) Preparation of a semipermantent mounting medium for fluorescent antibody studies. Virology 12: 316-317.

Schnapp, B. J., and T. S. Reese (1982) Cytoplasmic structure in rapid-frozen axons. J. Cell Biol. 94: 667-679.

Sobue, K., K. Kanda, M. Inui, K. Morimoto, and S. Kakiuchi (1982) Actin polymerization induced by calspectrin, a calmodulin-binding spectrin-like protein. FEBS Lett. 148: 221-225.

Switzer, R. C., III, C. K. Merril, and S. Shifrin (1979) A highly sensitive silver stain for detecting proteins and peptides in polyacrylamide gels. Anal. Biochem. 98: 231-237.

Triller, A., and H. Korn (1982) Transmission at a central inhibitory synapse. III. Ultrastructure of physiologically identified and stained terminals. J. Neurophysiol. 48: 708-735.

Tsukita, S., J. Usukura, S. Tsukita, and H. Ishikawa (1982) The cytoskeleton in myelinated axans: A freeze-etch replica study. Neuroscience 7: 21352147.

Tuttle, R., S. Masuko, and Y. Nakajima (1983) Membrane specializations at inhibitory and excitatory synapses on the goldfish Mauthner cell. Soc. Neurosci. Abstr. 9: 1027.

Wood, M. R., and D. S. Faber (1983) Granular coated vesicles in the goldfish Mauthner cell following axotomy. Brain Res. 273: 341-346. 